\title{
Variability Study in Rose Varieties
}

\author{
Priya Philip*, Mini Sankar, J. S. Minimol, Athira Baburaj and Jesabel George \\ Department of Floriculture and Landscaping, College of Horticulture, Kerala Agricultural \\ University, Vellanikkara, Thrissur - 680 656, India \\ *Corresponding author
}

\begin{tabular}{|l|}
\hline Key w o r d s \\
Rose, GCV, PCV, \\
Heritability, \\
Genetic advance \\
\hline Article Info \\
\hline $\begin{array}{l}\text { Accepted: } \\
\text { 07 June } 2019 \\
\text { Available Online: } \\
\text { 10 July } 2019\end{array}$ \\
\hline
\end{tabular}

\section{A B S T R A C T}

Rose, the flower queen is an important traditional as well as modern commercial flower crop. Since roses are adapted to a cooler climate of $18-28^{\circ} \mathrm{C}$, the cultivation is limited to the temperate regions and breeding for tropics is the need of the hour. The breeding programme should be focussed on heritable characters to get desired level of improvement in the progeny. Before going for any selection procedure, the genetic variability estimates like GCV, PCV, heritability and genetic advance has to be assessed for effective parental selection. Ten loose flower varieties viz. Arka Parimala, Sherba Gold, Mirabel, Vernish, Chersishma, Jadiov, Star Light, Spray Orange, Spray Yellow and Red varnish were grown under a naturally ventilated poly house of Department of Floriculture and Landscaping, College of Horticulture, Vellanikkara. The various quantitative traits were subjected to estimation of genetic parameters and the traits with high GCV and PCV indicates wide variability among the varieties for these characters. The characters number of flowers per sprout, number of flowers per plant, number of petals per flower and flower diameter at fully opened stage exhibited high heritability coupled with high genetic gain indicating that the expression of these characters are due to the additive gene effect and selection will be effective through these characters. The floral parameters of the ten rose varieties were subjected to cluster analysis and they were grouped in to six clusters at 6 percent similarity coefficient based on quantitative traits whereas the varieties were grouped into four clusters at 36 per cent similarity coefficient based on qualitative characters indicating wide variability among the selected rose varieties. The wide variability present in the population can be exploited in the selection process for developing new varieties suited to the tropics.

\section{Introduction}

Rose is the most popular economic flower crop and it is unique in its diversity in colour, types and fragrance.

There are around 200 species of roses and about 18,000 cultivars with exquisite shape, colour and fragrance (Gudin, 2000) all over the world. Roses are associated from birth to death of man and nowadays no function is complete without rose. Cut flower roses which are harvested along with its long stem at bud opening stage are widely used in flower decorations while loose flower roses which are harvested at its fully opened stage with its short pedicel are widely used in worship, making garlands and in perfumery industry. 
Rose is a native of temperate regions of northern hemisphere. Rose cultivation in plains is challenged by hot humid climate, pest and disease incidence and poor yield and quality due its lesser adaptability to a tropical climate. The research on roses should be prioritized in developing varieties with better colour, pest and disease resistance with focus on cost reduction and market intelligence to enhance productivity (Sivaramane et al., 2008). Parental selection is important in any crop improvement programme and the traits in which the parents are selected must have wide variability in the population.

The genetic estimates like GCV and PCV identifies the traits with wide variability among the population. Consistency in the expression will be achieved by selecting characters with high genotypic coefficient of variation. The estimate of heritability is an indication of degree of inheritance of the character to the next generation and it is the portion of variation that is due to Genetic advance and it provides an idea of the level improvement of the character in the progeny. High heritability coupled with high genetic gain is an indication that the expression of character is due to additive gene action and selection based on these characters will be effective in breeding programmes.

\section{Materials and Methods}

Ten loose flower varieties viz. Arka Parimala, Sherba Gold, Mirabel, Vernish, Charisma, Jadiov, Star Light, Spray Orange, Spray Yellow and Red Varnish were planted in pots filled with soil, sand and farm yard manure in 2:1:1 ratio. The floral characters like days taken for appearance to opening of flower buds, length of flower bud, diameter of flower bud, number of flowers per sprout, number of flowers per plant, number of petals per flower, flower diameter at fully opened stage, flower persistence, duration of flowering, yield of marketable flowers and fresh weight of the flower were observed. Observations on various floral parameters were recorded and subjected to analysis of variance and estimation of genetic parameters.

Genotypic coefficient of variation (GCV) were calculated according to the formula given by Burton (1952),

$\mathrm{GCV}=\frac{\sigma_{\mathrm{g} \times 100}}{\text { Grand mean }}$

Where, $\sigma \mathrm{g}$ is genotypic standard deviation Phenotypic coefficient of variation.

$\mathrm{PCV}=\frac{\sigma_{\mathrm{gx}} 100}{\text { Grand mean }}$

Where, $\sigma p$ is phenotypic standard deviation. The PCV and GCV value were categorised as described by Sivasubramanian and Menon (1973).

0 to $10 \%-$ low

10.1 to $20 \%$-moderate

$>20 \%$ - high

Where

$\mathrm{Vg}$ is genotypic variance and $\mathrm{vp}$ is phenotypic variance

$\mathrm{Vg}$

Heritability $(\mathrm{H} 2)=-------\mathrm{x} 100$

$\mathrm{Vp}$

Where, vg is genotypic variance and $\mathrm{vp}$ is phenotypic variance

Range of heritability was classified by Robinson et al., (1949)

0 to $30 \%$ - low

31 to $60 \%$ - moderate

$61 \%$ and above - high 
The genetic advance (GA) was calculated according to Johnson et al., (1955)

$\mathrm{GA}=\mathrm{K} \times \sigma \mathrm{p} \times \mathrm{H}^{2}$

Where, $\mathrm{K}=2.06$, a constant

$\sigma p=$ Phenotypic standard deviation

Genetic advance as percent of mean (GAM)

$\mathrm{GAM}=\frac{G A}{\text { Grand mean }} X 100$

The range of genetic advances percent of mean was categorized into

Low: less than $10 \%$

Moderate: $10-20 \%$

High: More than $20 \%$

The genetic association among genotypes based on qualitative and quantitative characters of rose varieties was measured by Euclidean distance using NTSYSpc software. Clustering analysis was carried out based on Jaccard`s similarity matrix and constructed a dendrogram by agglomerative method (Day and Edelsbrunner, 1984).

\section{Results and Discussion}

Among loose flowers, higher GCV and PCV were observed for the characters viz. number of flowers per sprout $(42.25,52.45)$, number of flowers per plant $(26.93,34.43)$, number of petals per flower (55.42,55.58), flower diameter at fully opened stage $(25.89,28.71)$, flower persistence $(20.98,27.65)$, yield of marketable flowers $(20.98,27.65)$, fresh weight of the flower $(61.69,93.84)$ and weight of petals per flower $(83.81,120.33)$. This results reveals that these characters were having wide variability among the population, which offers scope for selection. Similar results of high GCV and PCV for number of flowers per plant was reported by Sewaniya,
(2009). Among the loose flower varieties high heritability was reported for the characters viz. Number of petals per flower (99.45), length of flower bud(82.73), flower diameter at fully opened stage (81.32), number of flowers per sprout (64.89) and number of flowers per plant (61.19). These results are conformity with the findings of Sewaniya, (2009) for number of petals per flower. Moderate heritability was reported in characters viz. days taken for appearance to opening of flower bud (42.26), diameter of flower bud (47.57), yield of marketable flowers (57.58), fresh weight of the flower (48.50) and weight of petals per flower (48.50). Low heritability was reported in characters viz. flower persistence (10.86) and duration of flowering (21.59). These results are contradictory to the findings of Sewaniya, (2009) where more than 77 percent heritability was observed for all the characters studied. High genetic advance as percent of mean was reported in characters viz. Weight of petals per flower (120.23), number of petals per flower (113.84), fresh weight of the flower (83.55), number of flowers per sprout (70.11), yield of marketable flowers (40.47) and length of flower bud (27.31). These results indicate that these characters can be improved through simple selection. Similar findings of high GAM was reported in number of petals per flower by Sewaniya, (2009) and Janaki, (2013) while high GAM for fresh weight of flower was reported by Janaki, (2013). Medium GAM was reported in diameter of flower bud (15.21) where as low genetic advance as percent of mean was reported in duration of flowering (3.61), flower persistence (8.03) and days taken for appearance to opening of flower bud (9.43).

High heritability coupled with high GAM were noticed for characters, number of petals per flower $(99.43,113.84)$, number of flowers per sprout $(64.89,70.11)$, number of flowers per plant $(61.19,43.40)$ and flower diameter at fully opened stage $(81.32,48.10)$. 
Table.1 Mean values for floral characters

\begin{tabular}{|c|l|c|c|c|c|}
\hline \multirow{2}{*}{$\begin{array}{c}\text { SI. } \\
\text { NO. }\end{array}$} & \multicolumn{1}{|c|}{ Characters } & \multicolumn{2}{|c|}{ Range } & Mean value & CD (5\%) \\
\cline { 1 - 3 } $\mathbf{1}$ & $\begin{array}{l}\text { Days taken for emergence to } \\
\text { opening of flower buds }\end{array}$ & $\mathbf{1 6 . 6}$ & $\mathbf{1 3}$ & $\mathbf{1 4 . 2 8}$ & $\mathbf{1 . 8}$ \\
\hline $\mathbf{2}$ & Length of flower bud & $\mathbf{2 . 6}$ & $\mathbf{1 . 6}$ & $\mathbf{1 . 9}$ & $\mathbf{0 . 2}$ \\
\hline $\mathbf{3}$ & Diameter of flower bud & $\mathbf{2 . 2}$ & $\mathbf{3 . 2}$ & $\mathbf{1 . 0 5}$ & $\mathbf{0 . 1 8}$ \\
\hline $\mathbf{4}$ & Number of flowers/sprout & $\mathbf{9 . 9 5}$ & $\mathbf{2 3 . 3 8}$ & $\mathbf{1 1 . 4 1}$ & $\mathbf{6 . 0 4}$ \\
\hline $\mathbf{5}$ & Number of flowers /plant & $\mathbf{3 . 3 2}$ & $\mathbf{2 0 . 8 2}$ & $\mathbf{1 6 . 7}$ & $\mathbf{2 . 7 5}$ \\
\hline $\mathbf{6}$ & Number of petals per flower & $\mathbf{1 5 . 4}$ & $\mathbf{6 1 . 5}$ & $\mathbf{4 4 . 0 3}$ & $\mathbf{3 . 2}$ \\
\hline $\mathbf{7}$ & Flower diameter at fully & $\mathbf{2 . 8}$ & $\mathbf{6 . 7}$ & $\mathbf{4 . 0 3}$ & $\mathbf{0 . 9}$ \\
\hline & opened stage & & & & \\
\hline $\mathbf{8}$ & Flower persistence & $\mathbf{5 . 4}$ & $\mathbf{1 1 . 4}$ & $\mathbf{8 . 7 1}$ & $\mathbf{2 . 7}$ \\
\hline $\mathbf{9}$ & Duration of flowering & $\mathbf{1 7 . 3}$ & $\mathbf{2 0 2}$ & $\mathbf{1 9 3 . 2}$ & $\mathbf{5 . 9 8}$ \\
\hline $\mathbf{1 0}$ & Yield of marketable flowers & $\mathbf{1 8 . 1 7}$ & $\mathbf{4 0 . 7 2}$ & $\mathbf{2 3 . 0 3}$ & $\mathbf{5 . 2 9}$ \\
\hline $\mathbf{1 1}$ & Fresh weight of the flower & $\mathbf{1 . 1 3}$ & $\mathbf{3 . 1 4}$ & $\mathbf{2}$ & $\mathbf{0 . 3 0}$ \\
\hline $\mathbf{1 2}$ & Weight of petals /flower & $\mathbf{0 . 6 8}$ & $\mathbf{2 . 7 9}$ & $\mathbf{1 . 3 4}$ & $\mathbf{0 . 4 5}$ \\
\hline
\end{tabular}

Table.2 Genetic parameters for floral traits for loose flower

\begin{tabular}{|r|l|c|c|c|c|}
\hline $\begin{array}{c}\text { SI. } \\
\text { NO. }\end{array}$ & \multicolumn{1}{|c|}{ Character } & $\begin{array}{c}\text { GCV } \\
(\mathbf{\%})\end{array}$ & $\mathbf{P C V}(\mathbf{\%})$ & $\mathbf{H}^{\mathbf{2}(\%)}$ & $\mathbf{G A}(\mathbf{\%})$ \\
\hline $\mathbf{1}$ & $\begin{array}{l}\text { Days taken for emergence to } \\
\text { opening of flower buds }\end{array}$ & 6.73 & 9.90 & 46.26 & 9.43 \\
\hline $\mathbf{2}$ & Length of flower bud & 14.57 & 16.02 & 82.73 & 27.31 \\
\hline $\mathbf{3}$ & Diameter of flower bud & 12.62 & 17.49 & 47.57 & 15.21 \\
\hline $\mathbf{4}$ & Number of flowers/sprout & 42.25 & 52.45 & 64.89 & 70.11 \\
\hline $\mathbf{5}$ & Number of flowers /plant & 26.93 & 34.43 & 61.19 & 43.40 \\
\hline $\mathbf{6}$ & Number of petals per flower & 55.42 & 55.58 & 99.43 & 113.84 \\
\hline $\mathbf{7}$ & $\begin{array}{l}\text { Flower diameter at fully opened } \\
\text { stage }\end{array}$ & 25.89 & 28.71 & 81.32 & 48.10 \\
\hline $\mathbf{8}$ & Flower persistence & 11.83 & 35.89 & 10.86 & 8.03 \\
\hline $\mathbf{9}$ & Duration of flowering & 3.78 & 8.12 & 21.59 & 3.61 \\
\hline $\mathbf{1 0}$ & Yield of marketable flowers & 56.25 & 59.99 & 87.93 & 108.67 \\
\hline $\mathbf{1 1}$ & Fresh weight of the flower & 61.69 & 93.84 & 43.22 & 83.55 \\
\hline $\mathbf{1 2}$ & Weight of petals /flower & 83.81 & 120.33 & 48.50 & 120.23 \\
\hline
\end{tabular}


Table.3 Floral characters of rose varieties (Quantitative)

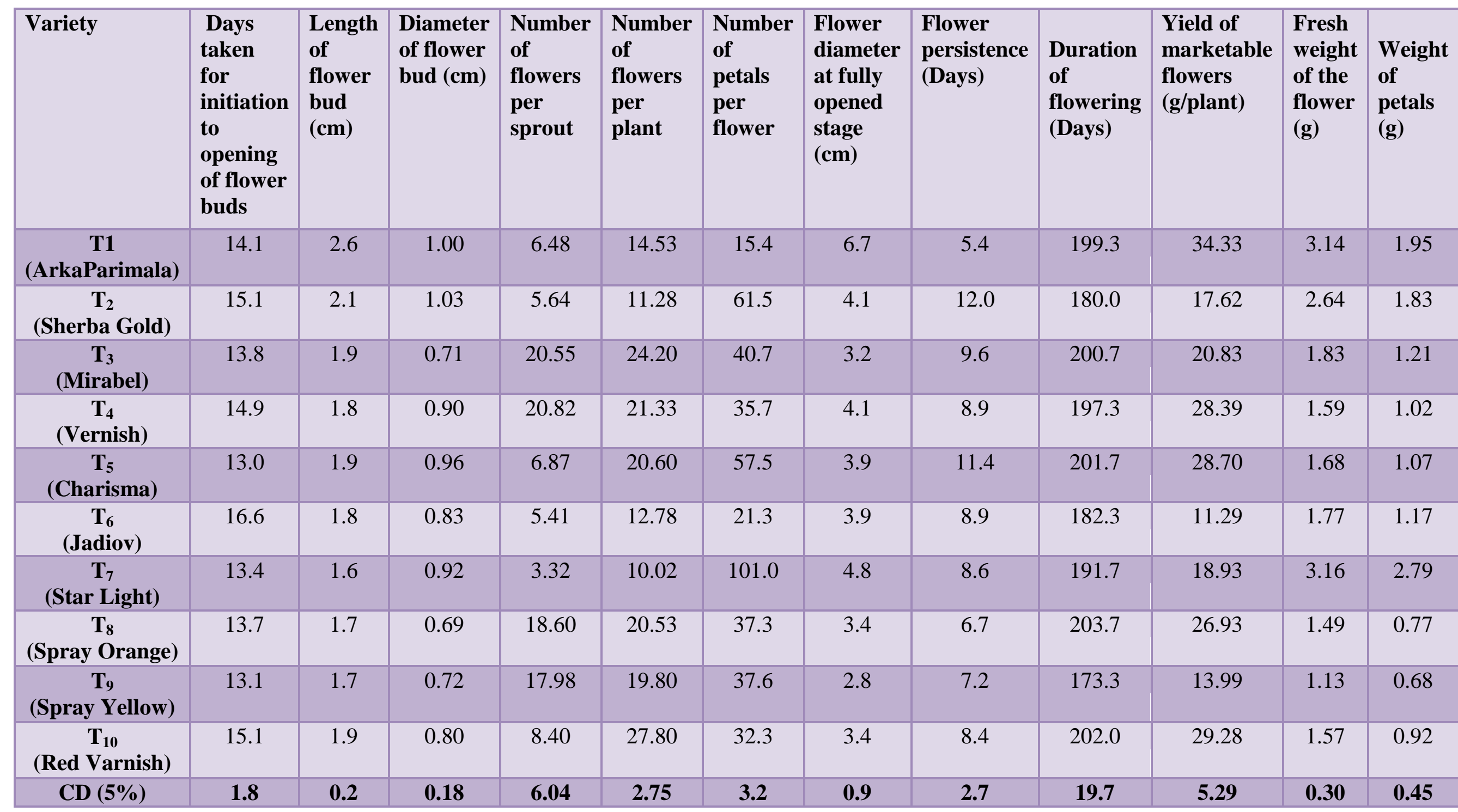


Table.4 Floral characters of rose varieties (Qualitative) characters

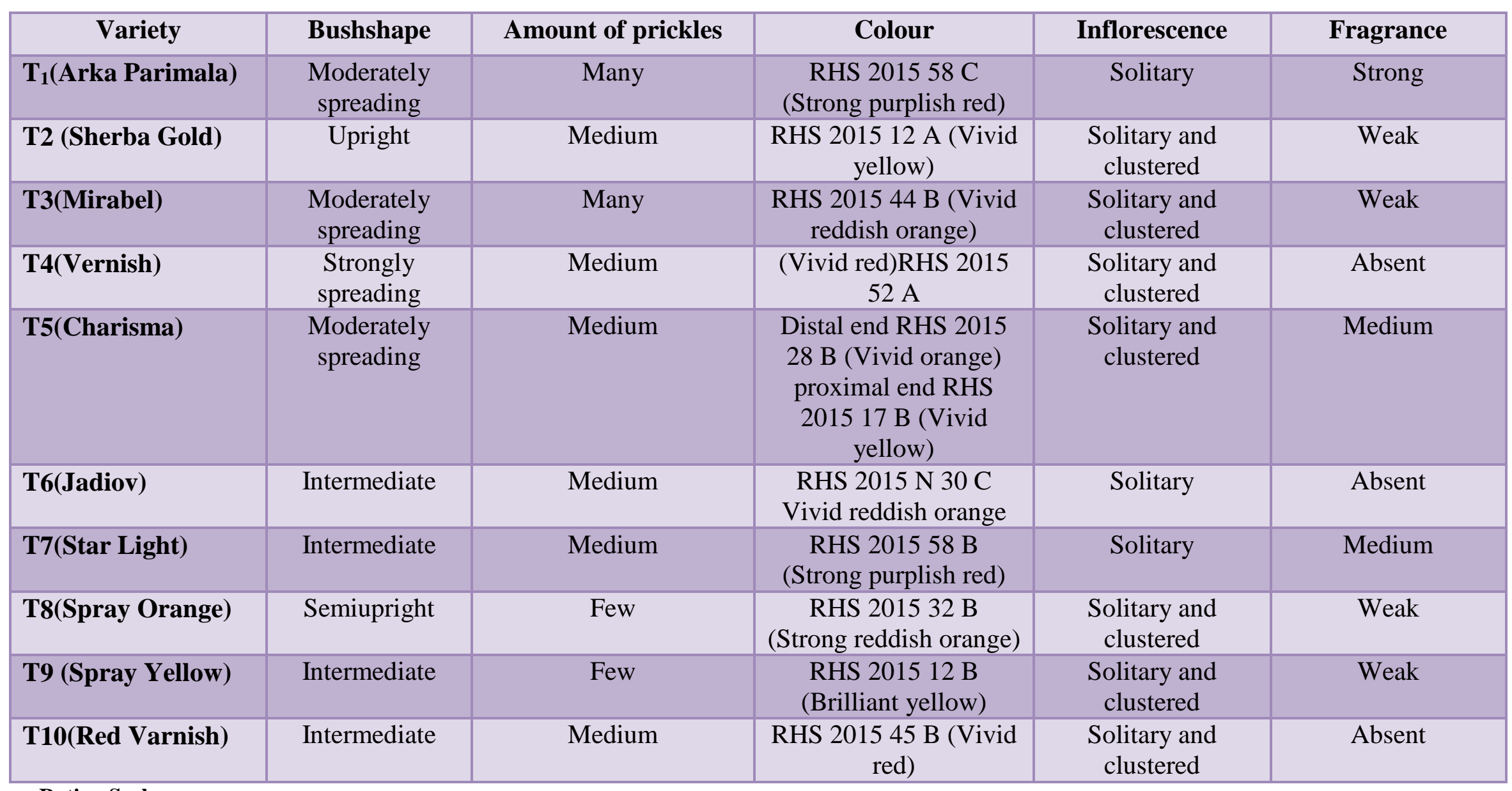

Rating Scale

- $\quad$ Flower colour: White blend-1, Yellowblend-2, Orange blend-3, Pinkblend-4, Red blend-5.

- Inflorescence type: Solitary or Clustered.

- $\quad$ Fragrance: 1-highly fragrant, 2- medium fragrant, 3-less fragrant, 4-no fragrance

- Bush shape: Upright-1, Semiupright-3, Intermediate-5, moderately spreading-7, Strongly spreading-9

- Amount of prickles: Absent-1, Few-3, Medium-5, Many- 
Fig.1 Dendrogram for quantitative characters of loose flower varieties

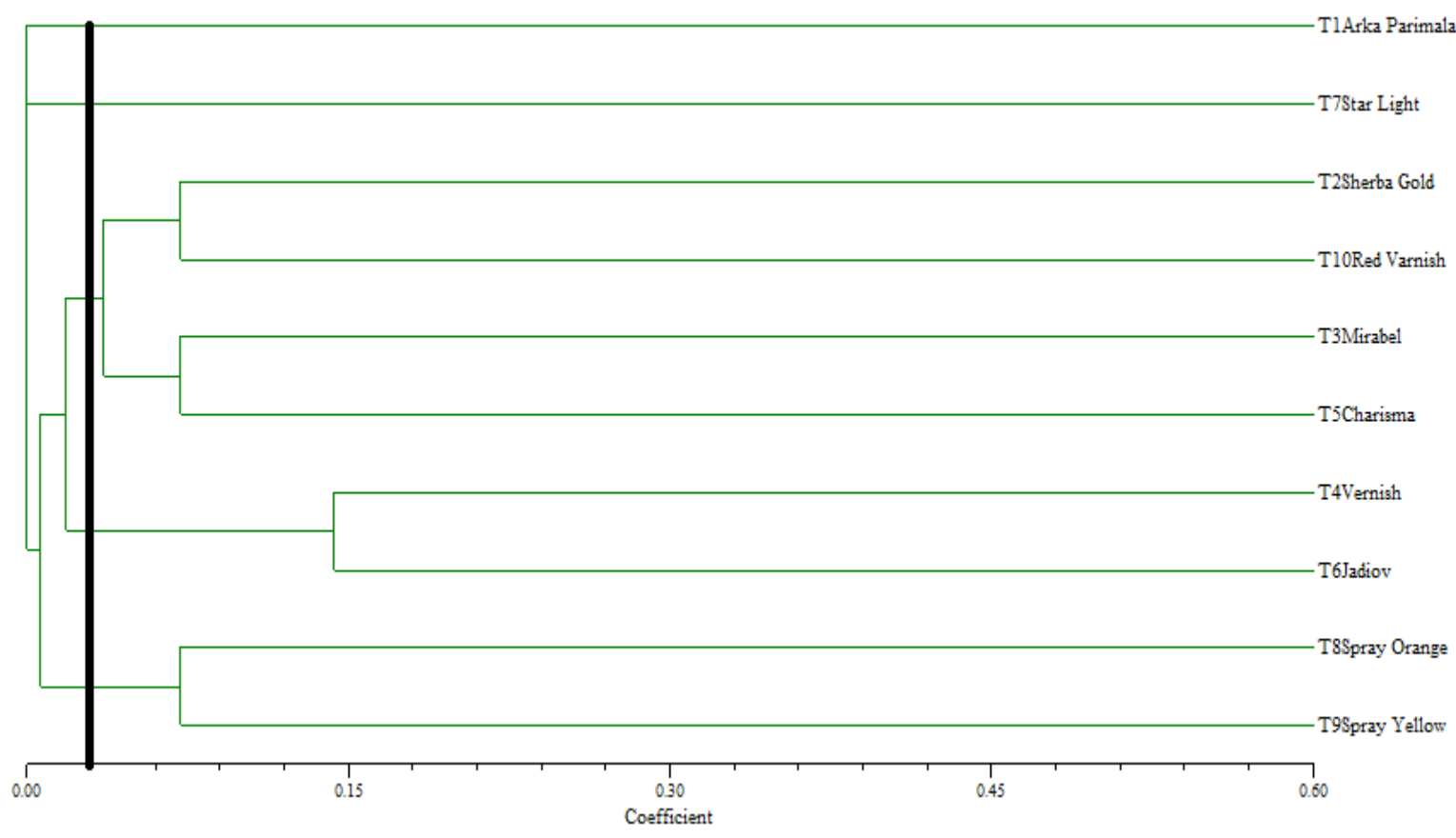

Fig.2 Dendrogram for qualitative characters of loose flower varieties

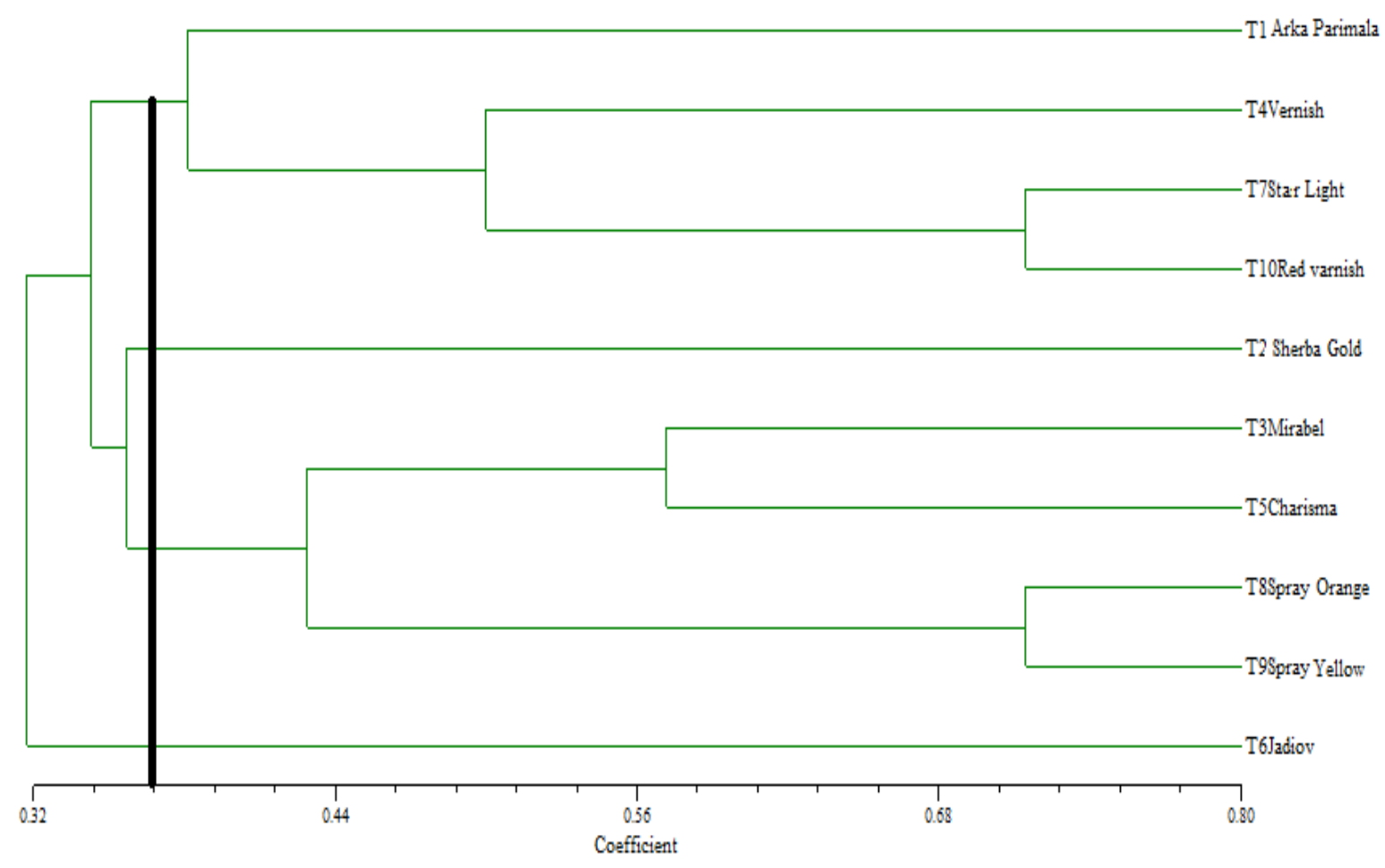


The high heritability along with high GAM indicates that the heritability is due to additive gene effect and selection based on these characters will be effective. This was in agreement with the findings of Gogoi et al., (2016) who observed high heritability coupled with high genetic gain in number of flowers per plant per year and reported that the characters controlled by additive gene effect. Similar findings of high amount of genetic variation and heritability for the vigour related traits in rose was reported by Yan et al., (2005).

From the estimated genetic parameters for loose flower varieties, it could be concluded that the characters viz. number of flowers per plant, number of petals per flower, flower diameter at fully opened stage having high GCV and PCV offers wide scope for selection. The high heritability coupled with high GAM results in effective selection to improve the performance of progeny in the next generation.

The loose flower varieties were clustered into six clusters (Fig. 1). Cluster I and II constituted by Arka Parimala and Star Light respectively and are distinct from other members. The varieties Sherba Gold and Mirabel formed cluster III and Charisma and Red varnish formed Cluster IV having similarity in flowering duration, flower persistence and number of flowers per plant. Cluster V was constituted by Vernish and Jadiov sharing similarity in duration of flowering, days taken for initiation to opening of flower buds, fresh weight of flower, flower persistence, length of flower bud and diameter of flower bud. The varieties Spray Orange and Spray Yellow having similar characteristics viz. duration of flowering, days taken for initiation to opening of flower buds, diameter of flower bud, length of flower bud, number of flowers per sprout, number of flowers per plant, number of petals per flower and flower diameter at fully opened stage formed cluster VI which indicated that improvement in any of the given characters parents are to be selected from different clusters. Kudori et al., (2015) also clustered forty seven damask rose genotypes were in to three groups based on twelve morphological traits.

The loose flower varieties were grouped into 4 clusters at 36 per cent similarity coefficient (Fig. 2). The varieties Arka Parimala, Vernish, Star Light and Red Varnish were grouped in to cluster II. They were similar with respect to characters viz. red colour blend. Cluster III had two varieties Mirabel and Charisma, Spray Orange and Spray Yellow sharing similar characteristics of dense leaf margin. Cluster II and IV constituted by Sherba Gold and Jadiov respectively with distinct qualitative characters. This is in conformity with the findings of Baliyan et al., (2014) who clustered twenty four genotypes of chrysanthemum based on nine quantitative and five qualitative traits.

\section{References}

Baliyan, D., Sirohi, A., Kumar, V., Malik, S., and Sharma, S. 2014. Comparative genetic diversity analysis in chrysanthemum: A pilot study based on morpho-agronomic traits and ISSR markers. Sci. Hortic. 167: 164-168.

Day, W. H. and Edelsbrunner, H. 1984. Efficient logarithms for agglomerative hierarchical clustering methods. $J$. Classification 1(1): 7-24.

Gudin, S. 2000. Rose genetics and breeding. Plant breed. Rev. 17: 159-189.

Janaki, K. 2013. Evaluation of Rosa hybrid cultivars for commercial cut flower production in coastal Andhra Pradesh. MSc (Ag) thesis, Y. S. R. Horticultural University, Andra Pradesh. 189p. 
Johnson, H. W., Robinson, H. F. and Comstock, R. E. 1955. Estimation of genetic and environmental variability in soybean. Agron. J. 47: 477-483.

Kudori, M. R., Rahmani, G. Tabaei-Aghdaei, S. R. Zeidabadi, D. D. Khoshroo, S.M., and Yazdi, M. S. 2015. Variation in Flower Yield and Morphological Characteristics of Damask Rose. $J$. Appl. Environ. Biol. Sci. 5(12): 208216.

Robinson, H. F., Comstock, R. E., and Harvey, P. H. 1949. Estimates of heritability and the degree of dominance in corn. Agron. J. 41: 353-359.
Sewaniya, P. 2009. Study on Variability, Correlation and Path analysis in HT Rose varieties at Malwa Plateau. M.Sc. (Ag.) Thesis, JNKV, Jabalpur (M.P.), $126 \mathrm{p}$.

Sivaramane, N., Kumar, A., Singh, D. R., and Arya, P. 2008. An economic analysis of traditional and hi-tech rose (Rosaspp.) cultivation. J. Ornam. Hortic. 11(1): 2126.

Sivasubrahmanian, S. and Menon, P. M. 1973. Genotypic and phenotypic variability in rice. Madras Agric. J. 60: 1093-1096.

\section{How to cite this article:}

Priya Philip, Mini Sankar, J.S. Minimol, Athira Baburaj and Jesabel George. 2019. Variability Study in Rose Varieties. Int.J.Curr.Microbiol.App.Sci. 8(07): 438-446. doi: https://doi.org/10.20546/ijcmas.2019.807.054 